\title{
Optimising economic and environmental outcomes: water quality challenges in Corner Inlet Victoria
}

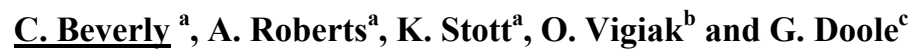 \\ ${ }^{a}$ Future farming System Research, Department of Environment and Primary Industries, Victoria \\ ${ }^{b}$ formerly Future farming System Research, Department of Environment and Primary Industries, Victoria \\ ${ }^{c}$ Centre for Environmental Economics and Policy, University of Western Australia, Western Australia \\ Email: craig.beverly@depi.vic.gov.au
}

\begin{abstract}
The Corner Inlet and Nooramunga Coastal Hotspot and Ramsar site is one of Victoria's important environmental assets. The seagrass beds are critically important to the ecosystem and these are under threat due to sediment and nutrient (nitrogen, $\mathrm{N}$ and phosphorus, $\mathrm{P}$ ) export from agricultural land management (mostly dairy and beef). The West Gippsland Catchment Management Authority (CMA), along with the Victorian and Australian governments, have responsibilities balancing the needs of local communities, including the economic viability of agricultural and fishing industries, and protecting the environmental values of the site through developing and implementing a Water Quality Improvement Plan (WQIP).
\end{abstract}

This study used science and local expert knowledge to develop a bioeconomic optimisation framework (using the General Algebraic Modelling System, GAMS) which informed a stakeholder panel overseeing the WQIP about the costs of achieving pollutant reduction targets under different land use and management options. These included traditionally funded activities (gully, stream and waterway fencing), agricultural 'bestmanagement practices' (BMPs) and land use change. A previously calibrated catchment model provided sub-catchment load estimates of total $\mathrm{N}(\mathrm{TN})$, total $\mathrm{P}$ (TP) and total suspended sediments (TSS). Development of a new land use layer allowed the proportions of dairy, beef and forestry to be ascribed. BMP effectiveness was assessed by expert opinion and the contribution of gully and waterways were estimated by extrapolating nearby modelling and mapping information based on similar soils. The change in operating profit was calculated assuming single representative dairy and beef systems and practices.

A stakeholder and technical panel comprising the CMA, Victorian and Australian governments, farming, fluvial ecology, hydrodynamics, seagrass ecology and catchment modelling expertise oversaw development of the WQIP. Choices about TN, TP and TSS reduction targets to be assessed were made based not only on estimated ecological outcomes, but also considering costs and political acceptability of implied land use and management changes. Three scenarios are presented: 'ideal at least cost' (best estimate of load reduction targets required to maintain seagrass); 'revised at least cost' which was half of the ideal target; 'revised with traditional activities only' (gully, stream and waterway fencing).

Achieving 'ideal' targets at least cost was estimated to result in an average loss in profit (cost) of $\$ 458 /$ ha over the grazed area $\left(757 \mathrm{~km}^{2}\right.$ ) and involved large scale retirement of agricultural land (over $96 \%$ dairy area and over $30 \%$ beef area). The 'revised' targets were estimated to cost $\$ 157 /$ ha and still required significant land retirement (75\% dairy land). Restricting land use activities to those traditionally funded and excluding land use change/retirement options increased costs from $\$ 157$ to $\$ 292 /$ ha. Overall these results imply that achieving large environmental gains involves major politically, socially and economically unacceptable impacts on grazing industries. The premise of 'win:win' outcomes, the basis of most publicly funded programs in Australia, is significantly challenged.

The results have been actively and adaptively used by the CMA to inform a realistic WQIP. Stakeholders recognised that the information base is imperfect and that refinement (finer scale catchment modelling and inclusion of heterogeneity in dairy and beef systems) could substantially reduce the estimated costs in achieving environmental outcomes. Bioeconomic modelling and active participation helped people understand the need for a more informed discussion about potential trade-offs between protecting environmental ecosystems and maintaining agricultural profitability. Policy choices involving targeted regulation to protect valuable ecosystems are likely to be needed, as is occurring elsewhere in the world.

Keywords: Decision Support System (DSS), bioeconomic optimisation framework, water quality 
Beverly et al., Optimising economic and environmental outcomes: water quality challenges in Corner Inlet Victoria

\section{INTRODUCTION}

The Corner Inlet and Nooramunga Coastal Hotspot and Ramsar Site (hereafter referred to as Corner Inlet) has outstanding environmental and social values and, as part of the broader Wilsons Promontory Region, supports tourism and commercial fishing, dairy, beef and plantation forestry industries. In 2005 in response to increasing concern for the health of the Ramsar site, the West Gippsland Catchment Management Authority (WGCMA) and Gippsland Coastal Board (GCB) commissioned the CSIRO to undertake an environmental audit of Corner Inlet and its catchments. The audit concluded that the values of the Ramsar site were threatened by inflows of nutrients and sediments from the catchment resulting from land use changes since European settlement.

In response to the CSIRO audit recommendations, and through lobbying, Corner Inlet was included on the list of National Water Quality Hotspots by the Australian Government. The outcome of this listing was that funding was able to be accessed through the Australian Government to conduct scientific investigations to further the knowledge and baseline data to understand and address water quality issues.

These investigations were completed as part of the Coastal Catchments Initiative and were designed to provide the scientific underpinning to the development of a Water Quality Improvement Plan (WQIP). Deciding on water quality targets to assess environmental progress was crucial. In addition to being sufficiently specific, measurable and time-bound, the target needed to have ecological significance and be linked to the major causes of environmental degradation. The extent and condition of seagrass was envisaged to provide the measurable indicator of aquatic ecosystem health, with decline linked to increasing sediment and nutrient inputs to receiving waters. Nutrient load reduction targets for nitrogen (N), phosphorus (P), and sediment (SS) were thus selected as the best available, specific and measurable water quality targets based on available monitoring information. The premise is that improving water quality from land management actions will have positive outcomes for the receiving waters; however, the precise relationships between catchment loads and the ecological condition of the receiving waters is not currently quantified.

This paper describes the development of a nonlinear optimisation model developed for the Corner Inlet region which was used in decision-making to agree on water quality targets. Input data was drawn from available biophysical models, expert assessment of nutrient management practice effectiveness and economic costings based on representative farms.

\section{THE CORNER INLET REGION}

The Corner Inlet Ramsar Site was split into two discrete regions because the stakeholder panel decided that different water quality targets should be set for each. These have been labelled as Corner Inlet and Nooramunga respectively (Figure 1).

\section{CATCHMENT MODELLING}

\subsection{Overview}

The Corner Inlet bioeconomic model utilised predictions of catchment streamflow, baseflow and loads (TN, TP, TSS) reported by Water Technology (2008) and developed within the E2 platform (Argent

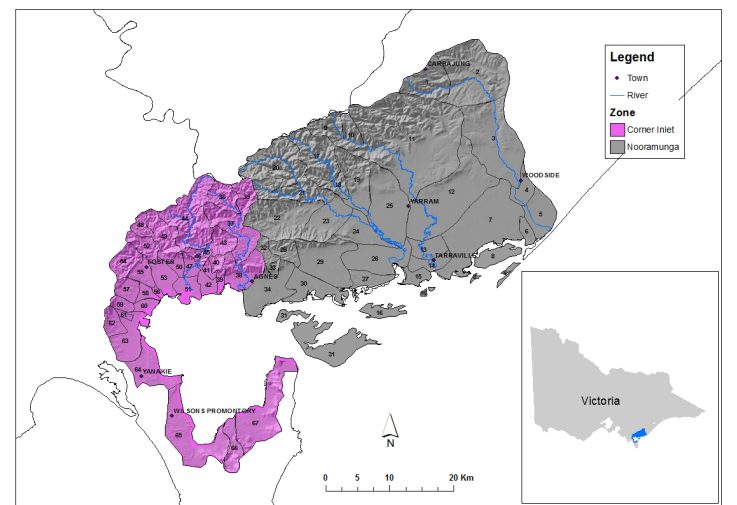

Figure 1. Location of the Corner Inlet Ramsar Site showing the Corner Inlet (blue) and Nooramunga (brown) catchments. et al., 2006), which was calibrated against existing water quality data and a sampling program designed to capture the effects of rainfall events. The Corner Inlet region was divided into 65 sub-catchments based on topography, river basins, land use and the location of existing water quality and flow monitoring stations. The E2 platform utilises the concept of functional units to describe areas that have similar hydrologic response and sediment and nutrient generation characteristics. Major land uses were based on the Bureau of Rural Science (BRS) land use mapping available at the time (Water Technology 2008); however, importantly, dairy and grazing land uses were not distinguished between, which was a major limitation as dairying is intensive and generates much greater nutrient surplus and hence potential losses.

Nutrient and sediment exports derived from the E2 model by Water Technology (2008) for each subcatchment were defined by Event Mean Concentrations (EMC) and a Dry Weather Concentration (DWC). 
Beverly et al., Optimising economic and environmental outcomes: water quality challenges in Corner Inlet Victoria

The E2 model was calibrated based on matching predicted streamflow and the export of SS, TKN, NOx, TP and DRP with measured stream gauge data (WaterTechnology, 2008). Initially, DWC and EMC values were designated using literature values and then calibrated against water quality data (VWMQN and Waterwatch) and an event based sampling program. Further calibration of the EMC and DWC values was undertaken in 2011 by Water Technology using additional event based monitoring data collected in the spring of 2010 and this final calibration was used in this study.

The modelling tasks undertaken in this study were categorised into six stages, namely:

1. Adaptation of the calibrated E2 model (land uses and sub-catchment estimates);

2. Estimate the \% effectiveness of alternative management practices;

3. Identify representative farming systems and estimate cost of implementing each best management practice;

4. Develop a bio-economic optimisation model;

5. Incorporate BMP and profit estimates with catchment model results;

6. Select and run scenarios.

\subsection{Adaptation of the calibrated E2 model (land use and sub-catchment estimates)}

The calibrated E2 model was used to generate input data for the optimisation model. The model used for this study was modified to include new land use data (the original BRS land use only had a 'dryland agriculture' classification). The new land use data mapped the extent of dairy and beef enterprises in each subcatchment. The flow and loads generated from these new classifications (we assumed dairy had three times the nutrient load of beef) were forced to match those flows and loads previously associated with the dryland agriculture classification. By so doing, the catchment model calibration was not altered. The partitioning of flow was based on the spatial extent of dairy and beef enterprises and assumed that groundcover was maintained at approximately the same level for these systems. Importantly, in order to match catchment loads, catchment specific EMC and DWC estimates for these new land uses were derived. An extension of the original E2 modelling was the assessment of gully risk mapping based on aerial photos and survey data. This mapping was correlated to streambank and gully erosion estimates derived using CatchMods in nearby catchments (Vigiak et al., 2011) to enable the estimation of streambank and gully TN, TP and TSS loads. Permanent waterway information was based on river network mapping and digital elevation modelling.

\subsection{Expert workshop to nominate effectiveness of best management practices}

The project relied on collaboration between researchers, extension officers and key community members and stakeholder groups. In the absence of information other than literature reviews which were not sufficiently specific to the local context, a workshop of technical experts was held to identify meaningful so-called 'best management practices' (BMPs) for reducing nutrient and sediment losses. Thirteen BMPs were identified. Some were relevant to either beef or dairy, with some relevant to both (Table 1). The BMPs were (1) nutrient application rates, (2) effluent collection, (3) effluent management, (4) management of tracks and crossings, (5) management of wet areas, (6) management of pasture cover, (7) restoring bare areas, (8) management of landslips and (9) transition to beef (in the case of dairy) or revegetation (in the case of beef). BMPs related to traditional works undertaken by the CMA were also included, namely (10) fencing of gullies, (11) fencing of permanent waterways, (12) fencing of ephemeral streams and (13) the construction of drainage lines. Effectiveness estimates in terms of percentage reduction for TN, TP and TSS were assigned to each BMP compared to the current practices relevant to both beef and dairy farms.

\subsection{Representative farms and costs}

Consultation with agronomists and producers in the study region suggested that three land-use enterprises be considered, namely dairy, beef and revegetation. The representative dairy farm was assumed to be 170 ha characterised as a predominantly perennial pasture-based dryland system with a milking area (MA) of 140 ha. The dairy herd comprised 270 cows with bought-in feed of 1.5 tonnes DM/year/cow. Milk production was assumed to be $445 \mathrm{~kg}$ milk solids (MS)/year/cow. For the beef system, the property size was assumed larger than the dairy property totaling 280 ha and was assumed to use clover exclusively to fix $\mathrm{N}_{2}$ to minimise the need to purchase supplementary feed. The stocking rate was 23-24 dry sheep equivalent (DSE)/ha, which is similar to the top $20 \%$ of farms participating in the Gippsland Livestock Farm Monitor, which are typically located in south Gippsland. 
Beverly et al., Optimising economic and environmental outcomes: water quality challenges in Corner Inlet Victoria

The annual net private benefit (+) or cost (-) of implementing each BMP on each dairy or beef representative farm was calculated relative to a baseline, this being the annual 'Operating Profit' (OP) for each system. The OP was calculated as gross income minus costs (including variable costs and fixed costs or overheads). The OP is a measure of the efficiency of resource use on the farming systems expressed in dollars per hectare (\$/ha/annum) in the case of BMPs 19 or dollars per kilometer in the case BMPs 10-13 (\$/ km). The baseline OP for the dairy and beef systems was obtained from the Dairy and Livestock Farm Monitor Projects for the Gippsland region. These are surveys of farm financial performance conducted on an annual basis. All reported OP estimates were adjusted for inflation using the ABARE producer price index (PPI) and expressed in 2011/12 Australian dollars (Table 1). The metric used to quantify the total net private benefits or costs of each BMP was the net present value (NPV), calculated over a 20year time horizon. A real discount rate of $4 \%$ was used, based on a $3.5 \%$ cash rate plus $2 \%$ allowance for risk less $1.5 \%$ for inflation.
Table 1: Profit (\$) of BMPs.

\begin{tabular}{|l|r|r|}
\hline & \multicolumn{1}{|c|}{ Dairy } & \multicolumn{1}{l|}{ Beef } \\
\hline Base case & 954 & 397 \\
\hline 1. Nutrient application rates & 980 & \\
\hline 2.Effluent collection & 930 & \\
\hline 3.Effluent management & 952 & \\
\hline 4.Tracks and crossings & 755 & 375 \\
\hline 5.Wet areas & 896 & \\
\hline 6. Pasture management (groundcover) & & 330 \\
\hline 7. Restoring bare areas & & 389 \\
\hline 8. Landslips & & 386 \\
\hline 9. Retire to biodiversity revegetation & $-1,693$ & $-1,244$ \\
\hline 10. Gully/tunnel erosion (per km) & $-4,513$ & $-4,513$ \\
\hline 11. Permanent waterways (per km) & $-6,367$ & $-5,438$ \\
\hline 12. Natural ephemeral streams (per km) & $-3,976$ & $-3,697$ \\
\hline 13. Constructed drainage lines (per km) & -312 & $-2,065$ \\
\hline
\end{tabular}

The costs of gully and streambank management were based on West Gippsland Catchment Management Authority data (Michelle Dixon, pers. comm.). These costs were divided between upfront and ongoing costs for maintenance. Revegetation with indigenous species was estimated to be $\$ 4,500 /$ ha with ongoing maintenance of $\$ 450 /$ ha to control pests and weeds. Fencing cost was estimated to be $\$ 8,500 / \mathrm{km}$, noting that both sides of gullies must be fenced to exclude stock. It was further assumed that dairy farms have already fenced $60 \%$ of gullies and $50 \%$ of permanent waterways and ephemeral streams. Opportunity costs associated with the foregone value of the fenced land were also included. The opportunity costs for dairy and beef farms was assumed to be $\$ 12,600 /$ ha and $\$ 6,286 /$ ha respectively (Dairy Industry Farm Monitor Project, 2010/11). The distance from gully, permanent waterways and ephemeral streams to a fence was assumed to vary from $100 \mathrm{~m}$ to $30 \mathrm{~m}$ for dairy and beef farms respectively.

\subsection{Optimisation model}

The optimisation model maximises total net benefits expressed as the difference between producer profit and regulatory costs for a given nutrient target (Equation 1). This cost-effectiveness approach, where emissions goals are sought at least cost, is common (e.g. Doole, 2012; Doole and Pannell, 2012) because it avoids the difficulty and cost of assessing the benefits associated with improved water quality. There are $a$ subcatchments in each catchment labeled $s c=[1,2 . ., a]$. The total land area is allocated to $b$ land use combinations labeled $l u=[1,2, \ldots, b]$. These land use combinations contain permutations of dairy and beef current and BMP options, plus transition from dairy to beef and beef to revegetation, totalling 20 land use permutations. Five decision variables describe the management options. First, the area allocated to each land use in each sub-catchment denoted by $A_{s c, l u}$. Second, the intensity with which gully erosion is managed in each sub-catchment denoted by $G_{s c}$, Third, the intensity with which streambank erosion is managed in each sub-catchment denoted by $S_{s c}$, Fourth, the intensity with which permanent waterway erosion is managed in each sub-catchment denoted by $W_{s c}$, Permanent waterways differ from streams in terms of erodibility and length of fencing. The intensity of gully, streambank and permanent waterway management is the percentage of the gully system or associated length that is fenced and revegetated. The fifth management option is constructed drains in each sub-catchment denoted by $D_{s c}$. Subscripts $e g$ refers to the number of gullies, es the number of streambanks, ew the number of permanent waterways and $e d$ the number the constructed drains. The cost $(\mathrm{A} \$$ ) of a given intensity of gully, streambank, permanent waterway and 
Beverly et al., Optimising economic and environmental outcomes: water quality challenges in Corner Inlet Victoria

constructed drain management within the sub-catchment is $c g^{n}{ }_{s c}^{n}, c s_{s c^{n}}^{n}, c w_{s c^{n}}^{n}$ and $c d_{s c^{n}}^{n}$ respectively. Total profit in each catchment $\left(\pi^{n}\right)$ is computed:

$$
\begin{aligned}
& \pi^{n}=\text { landuse profit } \mathrm{x} \text { landuse area }- \text { cost gully management }- \text { cost streambank management } \\
& \text { - cost of permanent waterway management - cost of constructed drains } \\
& =\sum_{s c^{n}=1}^{a^{n}} \sum_{l u^{n}=1}^{b^{n}} \pi^{n}{ }_{s c^{n}, l u^{n}} A^{n}{ }_{s c^{n}, l u^{n}}-\sum_{s c^{n}=1}^{a^{n}} \sum_{e g^{n}=1}^{d^{n}} c g^{n}{ }_{s c^{n}, e g^{n}} G^{n}{ }_{s c^{n}, e g^{n}}-\sum_{s c^{n}=1}^{a^{n}} \sum_{e s^{n}=1}^{f^{n}} c s^{n}{ }_{s c^{n}, e s^{n}} S^{n}{ }_{s c^{n}, e s^{n}} \\
& -\sum_{s c^{n}=1}^{a^{n}} \sum_{e w^{n}=1}^{d^{n}} c w_{s c^{n}, e g^{n}}^{n} W_{s c^{n}, e g^{n}}^{n}-\sum_{s c^{n}=1}^{a^{n}} \sum_{e d^{n}=1}^{f^{n}} c d_{s c^{n}, e s^{n}}^{n} D_{s c^{n}, e s^{n}}^{n}
\end{aligned}
$$

Contaminant loads (TC) are calculated as follows where C refers to either TN, TP and TSS and Gload, Sload, Wload and Dload refers to exports from gully, streambank, permanent waterway and constructed drains respectively:

$$
\begin{aligned}
T C^{n}=\sum_{s c^{n}=1}^{a^{n}} \sum_{l u^{n}=1}^{b^{n}} C_{s c^{n}, u^{n}}^{n} A^{n}{ }_{s c^{n}, l u^{n}}+ & \sum_{s c^{n}=1}^{a^{n}} C_{G L o a d}^{n} G_{s c}^{n}+\sum_{s c^{n}=1}^{a^{n}} C^{n}{ }_{S L o a d} S_{s c}^{n}+ \\
& \sum_{s c^{n}=1}^{a^{n}} C^{n}{ }_{\text {WLoad }} W^{n}{ }_{s c}+\sum_{s c^{n}=1}^{a^{n}} C^{n}{ }_{\text {DLoad }} D^{n}{ }_{s c}
\end{aligned}
$$

Optimisation involves maximisation of equation 1, subject to target emission constraints applied to equation 2. Additional constraints and assumptions included (1) bare areas occupy less than $10 \%$ of beef farms, (2) land slips occupy less than $1 \%$ of beef farms, (3) constructed drains are limited to $170 \mathrm{~m}$ per 1500 ha for dairy and $280 \mathrm{~m}$ per 200 ha for beef, (4) effluent collection occupies less than $1 \%$ of dairy farms and (5) effluent management only permitted on farms that adopt effluent collection practices and on those farms are limited to less than $50 \%$ of dairy farm area. Each model is solved using nonlinear programming with the CONOPT solver in the General Algebraic Modelling System (GAMS) (Brooke et al., 2008).

\subsection{Incorporation of BMP and profit estimates with catchment model results}

Input data for the optimisation model required catchment export loads for each constituent and profit information associated with each of the 14 combinations of the three alternative land uses (Section 3.2) for all sub-catchments. The 14 combinations relate to the base case and 13 BMP abatement options (Table 1). The base case export loads were derived using the E2 model, whereas the loads associated with each BMP options were calculated based on the BMP effectiveness estimates relative to the base case. Gully, streambank, ephemeral waterway and constructed drainage line loads were based on the CatchMods estimates.

\subsection{Scenarios}

Numerous abatement target, available budget and land use change scenarios were considered by the stakeholder panel. This paper will focus on four scenarios only, namely:

1. Ideal case: This represented the aspirational case in which the TN, TP and TSS percentage reductions were set based on ecologists 'best-bet' estimates for how much load reduction was needed to at least maintain the current extent and health of seagrass beds. Percentage reduction targets for Corner Inlet were 30, 30 and 10 respectively, while those for Nooramunga were 20, 20 and 20 respectively. The full costs of BMP implementation were allowed for, including practices not currently funded. Land use change from dairy to beef and from beef to forest was allowed to meet the target at least cost.

2. Revised case: In this scenario the TN, TP and TSS percentage reductions were set at approximately half of the Ideal case, namely 15, 15 and 10 respectively for Corner Inlet, while those for Nooramunga were 10, 10 and 15 respectively. BMP costs and land use change was allowed, as per the Ideal case.

3. Constrained Revised case. Costs were constrained to approximately those of the Revised scenario and in addition land use change from dairy to beef and from beef to forest was not permitted. 
Beverly et al., Optimising economic and environmental outcomes: water quality challenges in Corner Inlet Victoria

4. Limited budget case: The available annual budget was constrained to approximately $\$ 300 \mathrm{k} / \mathrm{year}$. Land use change was allowed to meet the available budget and maximise profit.

\section{RESULTS}

\subsection{Costs and land use implications of achieving targets}

The annual operating profit earned on farms before attempting to meet nutrient reduction targets was estimated to be $\$ 39 \mathrm{M} /$ year (Corner Inlet \$14.2 M/year, Nooramunga $\$ 24.8 \mathrm{M} /$ year). Targets achieved and the loss in profit for each scenario considered are summarised Table 2. The percentage of dairy estimated as required to transition to beef in order to meet the abatement and budget targets for scenarios 1, 2 and 4 respectively were $97 \%, 76 \%$ and $5 \%$; scenario 3 enforces no transition. In addition, the percentage of beef area estimated to be retired to meet the abatement and budget targets for scenarios 1, 2 and 4 respectively was $34 \%, 5 \%$ and $0 \%$. The areas assigned to traditional CMA nutrient abatement activities (fencing of gullies, streams and permanent waterways) represented $2 \%, 1 \%$ and $6 \%$ of current dairy areas for scenarios 1, 2 and 3; scenario 4 selected other more cost-effective options. The corresponding activities assigned to current beef farms were $0.8 \%, 0.5 \%$ and $3.4 \%$ of current dairy areas for scenarios 1,2 and 3 with scenario 4 allocating no resources. Constructed drains were only selected as options in scenarios 1 and 2 representing $0.1 \%$ and less respectively across the entire study area.

\subsection{Land use and management changes}

Results are also available for individual sub-catchments. They provide users with a quantitative assessment of the spatial distribution of nutrient and sediment loads, area transitioned to each BMP/enterprise and profit loss/cost associated with each scenario. As an example, Figures 2 and 3 show the percentage area within each sub-catchment required to adopt effluent collection and management for the constrained revised and limited budget scenarios respectively.

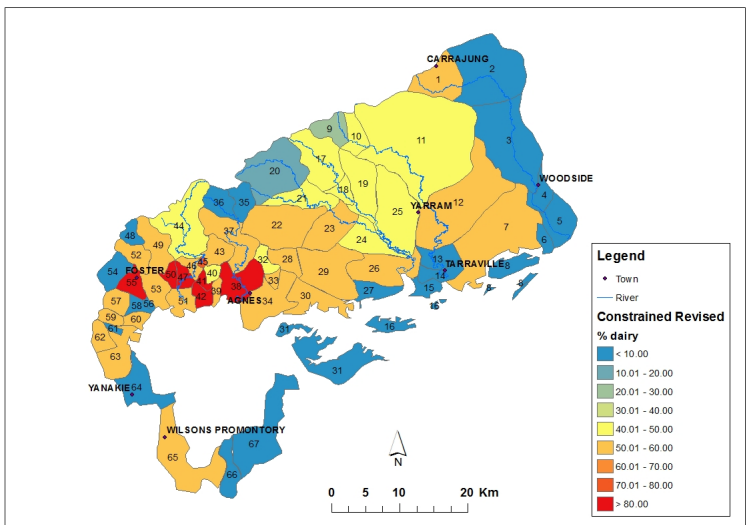

Figure 2. Percentage area within each sub-catchment required to adopt effluent collection and management under the constrained revised scenario.

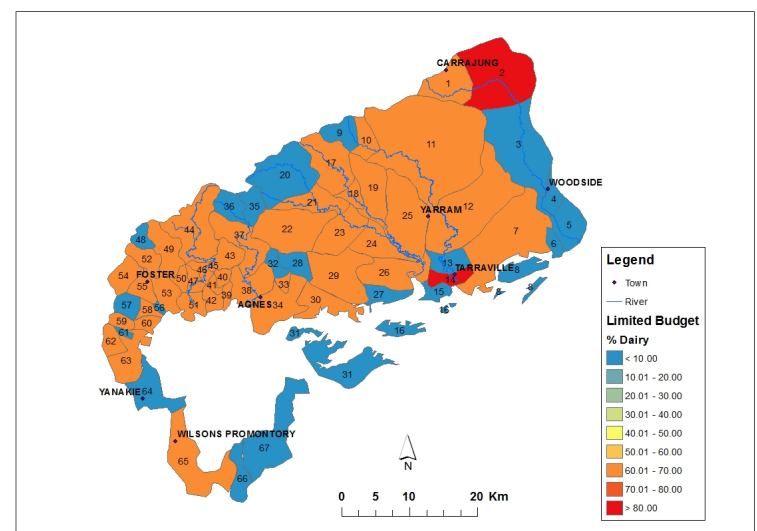

Figure 3. Percentage area within each sub-catchment required to adopt effluent collection and management under the limited budget scenario. 
Beverly et al., Optimising economic and environmental outcomes: water quality challenges in Corner Inlet Victoria

\section{DISCUSSION AND CONCLUSIONS}

Ideal targets cannot be achieved without a massive loss in profit and politically unacceptable land use changes out of agriculture. So-called 'win:win' outcomes appear not possible and highlight the need for a more informed and long-term discussion about the need for increased regulation and land use change away from grazing industries if environmental assets are to be maintained. Another key finding is that traditional CMA works (such as streambank and river fencing) are a costly and less effective measure to abate nutrient losses, relative to BMP adoption and land use change. These activities were never selected as least-cost options under a low budget. This arose due to the interaction between cost and abatement efficiencies whereby $\mathrm{N}$ and $\mathrm{P}$ can be reduced more cost-effectively by directly addressing high nutrient generating land uses (dairy in particular). Even under budgets as low as $\$ 300,000 /$ year, some land use change away from dairying is selected as the best way to reduce nutrient loads at least cost.

A comparison between the constrained revised and limited budget scenarios highlighted that transition from dairy to beef and from beef to revegetation was estimated to be almost $\$ 12 \mathrm{~m} /$ year more cost effective than not allowing land use change to achieve similar abatement reduction (costs were 40 times greater). This implied that placing restrictions on land use and management options, particularly on land use change, could significantly reduce the cost of achieving water quality outcomes compared with current investment approaches. These results also indicate that adoption of BMPs alone will be insufficient to meet significant (and in some cases measurable) nutrient and sediment abatement targets.

Results from this study concluded that optimising environmental outcomes without markedly reducing agricultural profitability will require very tight and careful targeting of public investment. Only very small nutrient reductions (maximum several percent) are feasibly achievable with small (e.g. \$300,000/year) budgets. CMA investment into 'traditional' activities such as waterway fencing will likely result in very limited nutrient reduction benefits whilst limiting management interventions to only BMPs also appear costly for limited (5\% or less) nutrient reduction targets. For greater confidence in the results, and in the design of better targeted intervention strategies, finer-scale physically-based catchment modeling tools than the E2 model are required. Such strategies could then be used more confidently to initiate a long-term discussion about the trade-offs between agricultural production and the environment. Currently, a dialogue relating to these outcomes is only possible given the development of the bioeconomic optimisation tool described here and the interaction between researchers from various disciplines and stakeholders.

\section{ACKNOWLEDGMENTS}

The Corner Inlet Water Quality Plan is majority funded by the Australian Government's Natural Heritage Trust. The authors acknowledge the efforts of Michelle Dickson of the West Gippsland CMA who managed the project and provided considerable time to this work. Thanks also to Jane McInnes for E2 modelling and GIS support.

\section{REFERENCES}

Argent, R.M., Murray, N., Podger, G.M., Perraud, J.M. and Newham, L. (2006). E2 catchment modelling software component modules, CRC for Catchment Hydrology, Australia

Brooke, A., Kendrick, D., Meeraus, A. and Raman, R. (2008). GAMS-A user's Guide. GAMS Development Corporation, Washington, DC.

Doole, G.J. (2012). Cost-effective policies for improving water quality by reducing nitrate emissions from diverse dairy farms: An abatement-cost perspective, Agricultural Water Management, 104, 10-20.

Doole, G.J. and Pannell, D.J. (2012). Empirical evaluation of nonpoint pollution policies under agent heterogeneity: regulating intensive dairy production in the Waikato region of New Zealand, Australian Journal of Agricultural and Resource Economics, 56, 82-101.

Vigiak, O., McInnes, J., Beverly, C., Thompson, C., Rees, D. and Borselli, L. (2011). Impact of soil erodibility factor estimation on the distribution of sediment loads: the LaTrobe River catchment case study. In Chan, F., Marinova, D., Anderssen, R.S. (eds) MODSIM2011 19th International congress on modelling and simulation. Modelling and Simulation Society of Australia and New Zealand, Perth, Australia 12-16 December 2011, 1930-1936. [http://www.mssanz.org.au/modsim2011/E3/vigiak.pdf]

Water Technology (2008). Corner Inlet Sediment and Nutrient Modelling, Final Report, Report No. J677/R05, December 2008, pp.366. 